\title{
Author Correction: Transplanted miR-219-overexpressing oligodendrocyte precursor cells promoted remyelination and improved functional recovery in a chronic demyelinated model
}

\author{
Hong-Bin Fan ${ }^{1,2}$, Li-Xia Chen ${ }^{3}$, Xue-Bin Qu ${ }^{1}$, Chuan-Lu Ren ${ }^{4}$, Xiu-Xiang Wu ${ }^{1}$, Fu-Xing Dong ${ }^{1}$, \\ Bao-Le Zhang ${ }^{1}$, Dian-Shuai Gao ${ }^{1} \&$ Rui-Qin Yao ${ }^{1}$
}

Correction to: Scientific Reports https://doi.org/10.1038/srep41407, published online 01 February 2017

This Article contains an error in the affiliation for Li-Xia Chen, which is incorrectly listed as 'Clinical Laboratory, Xuzhou Center Hospital, Xuzhou, 221000, China'. The correct affiliation is listed below:

Clinical Laboratory, Xuzhou TCM Hospital Affiliated to Nanjing University of Chinese Medicine, Xuzhou, 221000, China.

(c) (i) Open Access This article is licensed under a Creative Commons Attribution 4.0 International License, which permits use, sharing, adaptation, distribution and reproduction in any medium or format, as long as you give appropriate credit to the original author(s) and the source, provide a link to the Creative Commons license, and indicate if changes were made. The images or other third party material in this article are included in the article's Creative Commons license, unless indicated otherwise in a credit line to the material. If material is not included in the article's Creative Commons license and your intended use is not permitted by statutory regulation or exceeds the permitted use, you will need to obtain permission directly from the copyright holder. To view a copy of this license, visit http://creativecommons.org/licenses/by/4.0/.

(C) The Author(s) 2018

\footnotetext{
${ }^{1}$ Department of Cell Biology and Neurobiology, Xuzhou Key Laboratory of Neurobiology, Jiangsu Key Laboratory of New Drug Research and Clinical Pharmacy, Xuzhou Medical University, Xuzhou, 221009, China. ${ }^{2}$ Department of Neurology, Affiliated Hospital of Xuzhou Medical University, Xuzhou, 221002, China. ${ }^{3}$ Clinical Laboratory, Xuzhou TCM Hospital Affiliated to Nanjing University of Chinese Medicine, Xuzhou, 221000, China. ${ }^{4}$ Department of Laboratory, No. 100 Hospital of CPLA, Suzhou, 215007, China. Hong-Bin Fan and Li-Xia Chen contributed equally. Correspondence and requests for materials should be addressed to R.-Q.Y. (email: wenxi_yao@163.com)
} 